\title{
Emoções, Inteligência e Negociação: um Estudo Empírico sobre a Percepção dos Gerentes Portugueses
}

\author{
Filipe Jorge Ribeiro de Almeida \\ Filipe João Bera de Azevedo Sobral
}

\section{Resumo}

A investigação sobre negociação no contexto empresarial tem-se concentrado nos aspectos processuais e de decisão, ignorando o estudo das características individuais do negociador. Alguma literatura mais recente destaca o impacto decisivo que o perfil da inteligência pode ter nos resultados da negociação. Este trabalho tem como objetivo analisar a importância da Inteligência Cognitiva e da Inteligência Emocional nas negociações em contexto empresarial. Para o efeito, foi realizado um estudo empírico das percepções dos gerentes das 500 maiores empresas portuguesas sobre a importância de algumas características da inteligência e o papel da emoção na negociação. Os resultados revelam que os gerentes atribuem maior importância aos aspectos cognitivos do que aos aspectos emocionais. É igualmente sugerido que o controle das emoções e da sua visibilidade é determinante para o êxito do negociador; mas a sua manipulação é um comportamento reprovável no ambiente negocial. Com esta pesquisa descritiva e exploratória, pretende-se lançar pistas para investigações futuras sobre a importância da emoção e da inteligência nos processos negociais.

Palavras-chave: negociação; inteligência; cognição; emoção.

\begin{abstract}
The research on negotiation in business environment has been focused mainly in the negotiation processes and decision making issues, neglecting the role of personal characteristics. Recent research has drawn attention to the impact of the negotiator intelligence on negotiation outcomes. This paper aims to analyze the importance of Cognitive Intelligence and Emotional Intelligence on business context negotiations. For this purpose, it was conducted an empirical research on the perceptions of top management executives of the 500 largest Portuguese companies, inquiring about the importance of personal characteristics and emotion on negotiation outcomes. Results show that managers emphasize cognitive over emotional aspects. It is also suggested that the control of emotions and their visibility have a positive impact on negotiator's success, even though emotional manipulation is disapproved as a negotiation tactic. This study has descriptive and exploratory purposes, contributing to develop foundations for future research that explores the role of emotion and intelligence in negotiation.
\end{abstract}

Key words: negotiation; intelligence; cognition; emotion. 


\section{INTRODUÇÃO}

A negociação é uma realidade do cotidiano empresarial. Estima-se que os gestores gastem aproximadamente $20 \%$ do seu tempo em negociações e que, provavelmente, esses $20 \%$ afetam os restante $80 \%$ das suas atividades (BARON, 1989). Mintzberg (1973), no seu estudo sobre as funções-chave da gestão, identifica a negociação como tarefa fundamental na atividade empresarial. É, portanto, aceitável admitir que a capacidade para negociar eficazmente seja uma competência indispensável para o êxito da atuação de qualquer gestor ou gerente empresarial.

A perspectiva dominante nos trabalhos de investigação sobre negociação publicados nos últimos anos concentra a atenção nos processos de decisão, desvalorizando as características pessoais do negociador enquanto fator determinante do resultado da negociação. Esta incidência nos aspectos formais do processo negocial é frequentemente justificada com o argumento da imobilidade das características pessoais e de personalidade que, não sendo modificáveis, limitam as possibilidades de estudo sobre o perfil individual otimizador de resultados (BAZERMAN; CURHAN; VALLEY, 2000). No entanto, é indiscutível que a interação entre seres humanos envolve sempre a construção de percepções sobre o outro que podem influenciar (e, em muitas situações, de forma decisiva) o resultado dessa interação. Num processo negocial, dependendo do grau de complexidade da negociação, as características individuais podem ser determinantes na construção de percepções que favoreçam ou desfavoreçam o desenvolvimento positivo da interação das partes envolvidas. Se a negociação for presencial, como de fato acontece na maioria dos casos, o perfil individual, social e psicológico dos negociadores ganha uma relevância reforçada que não deve ser negligenciada. É verdade que algumas características pessoais tendem a ser estáveis em cada indivíduo mas, em situações onde é possível escolher o negociador que representa uma das partes, essas características podem ser determinantes na escolha da pessoa mais indicada que maximize as possibilidades de êxito da negociação (FULMER; BARRY, 2002).

As características individuais mais estudadas neste contexto são, entre outras, a estrutura moral dos valores sociais (OLEKANS; SMITH, 1999), a predisposição para o compromisso (DE DREU; KOOLE; OLDERSMA, 1999), o gênero (KRAY; GALINSKY; THOMPSON, 2001) e a auto-estima (KRAMER; POMMERSENK; NEWTON, 1993). A inteligência, nas suas diversas dimensões, tem sido uma característica do negociador merecedora de atenção reduzida (FULMER; BARRY, 2002). Mesmo os autores que se dedicam ao estudo da 
inteligência e do seu impacto nos processos negociais têm concentrado a análise na dimensão cognitiva da inteligência, desvalorizando a interferência dos aspectos emocionais nestes contextos (PUTNAM, 1994). No entanto, cada vez mais os investigadores reconhecem que os aspectos emocionais são essenciais em negociação (OGILVIE; CARSKY, 2002; THOMPSON, 2001). A negociação é tipicamente uma situação emocional onde os participantes experienciam um conjunto de sentimentos que têm impacto no processo e nos resultados da negociação (HEGTVEDT; KILLIAN, 1999; VAN KLEEF; DE DREU; MANSTEAD, 2004).

O objetivo deste trabalho consiste em estudar a importância da Inteligência na negociação, distinguindo os aspectos Cognitivos dos aspectos Emocionais. Propõe-se uma abordagem da Inteligência Cognitiva e da Inteligência Emocional a partir das percepções dos gerentes portugueses sobre a importância destas características nas negociações que ocorrem ao nível da administração das empresas. Esta pesquisa visa lançar as bases para o desenvolvimento de estudos posteriores que analisem em profundidade o papel decisivo que a emoção parece desempenhar no âmbito da negociação em ambiente empresarial.

\section{A Inteligência Cognitiva}

A Inteligência Cognitiva (IC) constitui uma das principais dimensões da psicologia humana que tem servido como indicador de capacidade intelectual e tem representado a inteligência individual na generalidade das aplicações do conceito no âmbito da investigação em ciências empresariais. Gottfredson (1997) define a IC como uma capacidade mental de espectro conceptual que envolve a capacidade de raciocínio, de planejamento, de resolução de problemas, de pensamento abstrato, de compreensão de idéias complexas, de aprendizagem rápida e a partir da experiência. Trabalhos anteriores referem-se à IC como estando relacionada com a capacidade individual de apreender e processar informação (REE; EARLES, 1991). Apesar de alguns trabalhos sugerirem uma forte relação positiva entre a IC e o desempenho dos gestores na tomada de decisões - especialmente em situações de mudança inesperada - (LEPINE; COLQUITT; EREZ, 2000), a IC é uma dimensão psicológica cujo impacto nos processos negociais tem sido pouco estudado, apresentando mesmo resultados empíricos que questionam a sua relevância no campo específico da negociação (BARRY; FRIEDMAN, 1998).

O estudo da inteligência através da IC assume frequentemente uma abordagem psicométrica baseada nos resultados da utilização de testes cientificamente 
validados e de aplicação tendencialmente universal. Na investigação em negociação, foram poucos os trabalhos que, desde a década de setenta do século XX, mediram a IC através de métodos psicométricos convencionais (FULMER; BARRY, 2002). Como exceções recentes podem destacar-se os trabalhos de Barry e Friedman (1998) e de Kurtzberg (1998), que encontraram fortes indícios empíricos para a existência de uma relação entre a IC (medida através dos resultados obtidos no GMAT - Graduate Management Achievement Test) e o resultado global alcançado num processo de negociação. No entanto, apesar da abordagem psicométrica ter permitido a utilização mais alargada do conceito de inteligência em inúmeros estudos, o esforço para resumir a inteligência num indicador numérico resultante da combinação de pontuações obtidas em testes tem sido igualmente alvo de críticas. Alguns autores sublinham a limitação desta perspectiva por ignorar aspectos subjetivos e ainda de mensurabilidade pouco exata que também caracterizam a capacidade mental humana (NEISSER et al., 1996).

Apesar das limitações que o conceito de Inteligência ainda apresenta em termos da clareza da sua definição e da validade dos critérios de medida utilizados, é aceitável admitir que, sendo a negociação uma tarefa que consiste na recolha de informação, sua análise e conseqüente tomada de decisões, a capacidade cognitiva tem impacto relevante na explicação dos resultados negociais. Os negociadores com maior complexidade cognitiva diferenciam mais alternativas, integrando, interpretando e relacionando com mais facilidade e clareza a informação fragmentada de que dispõem (PRUITT; LEWIS, 1975). Schmidt et al. (1988) confirmam esta idéia, concluindo que indivíduos com maior complexidade cognitiva são melhores para adquirir informação relevante que facilite a resolução de problemas. Segundo Jesuíno (1992), esta capacidade pode facilitar a apresentação de propostas mutuamente benéficas, concretizadas em soluções integrativas que satisfaçam ambas as partes. Fulmer e Barry (2002) sugerem que a IC pode, de fato, desempenhar um papel decisivo em situações de negociação complexa, prolongada no tempo, com diferentes partes envolvidas, diversos objetivos e eventualmente com pressões para uma finalização em prazos determinados. Mas este papel decisivo implica conhecer os processos cognitivos subjacentes ao comportamento humano e minimizar os erros decorrentes de uma racionalidade limitada. A capacidade para manter uma atitude racional ao longo do processo negocial é uma característica essencial para se negociar com eficácia (NEALE; BAZERMAN, 1991). Como defendem estes autores, os negociadores que queiram ser bem sucedidos têm de compreender e reduzir os erros cognitivos que possam enviesar a racionalidade do seu processo de tomada de decisão. Caso contrário, poderão não explorar as alternativas que melhor defendem os seus interesses e, consequentemente, fazer opções que não maximizam os seus resultados (BAZERMAN; NEALE, 1992). 


\section{A Inteligência Emocional}

O conceito de inteligência é habitualmente confundido com o sentido restrito da IC. Alguns autores têm contribuído para uma compreensão mais alargada da inteligência, propondo o seu desdobramento em diversas dimensões. A teoria de Sterneberg (1988) sugere a interação de três aspectos da inteligência: o processamento interno de informação, a capacidade de adequar competências individuais às condições do meio envolvente, e a capacidade para lidar com situações inesperadas. Anteriormente, já Gardner (1983) havia ampliado o conceito, dispensando menos atenção aos processos mentais envolvidos e distinguindo sete tipos de inteligência a que chamou inteligências múltiplas: lógico-matemática; lingüística; corporal sinestésica; espacial; musical; interpessoal; e intrapessoal. Apesar da visão multifacetada que confere ao conceito até então monolítico de inteligência, Gardner ainda apóia a sua teoria numa visão cognitiva da inteligência, orientada para a compreensão do mundo a partir da linguagem, da expressão, da análise dos motivos e da interpretação de hábitos. Esta ênfase na cognição não exclui, no entanto, a identificação de duas inteligências que se tornariam os elementos centrais da Inteligência Emocional: as inteligências interpessoal e intrapessoal.

Baseado nas inteligências múltiplas de Gardner, o modelo de Inteligência Emocional (IE) foi apresentado pela primeira vez em 1990 por Salovey e Mayer (1990), propondo uma arquitetura conceitual da inteligência não-cognitiva que viria quebrar definitivamente o monopólio da IC nos estudos sobre a inteligência. A proposta inovadora destes autores respeitava à percepção, compreensão e regulação de emoções do próprio indivíduo e dos outros. O conceito de IE ganharia projeção mundial a partir de 1995, com as contribuições de Goleman (1995) que, apoiado nos trabalhos exploratórios de Gardner e na modelização de Salovey e Mayer, combinou as dimensões intrapessoal e interpessoal da inteligência e desenvolveu uma teoria abrangente sobre o papel das emoções na interpretação da inteligência. Assim, segundo Goleman, na dimensão intrapessoal destacam-se as componentes de autoconhecimento e de autocontrole das emoções que se referem à capacidade de compreender e distinguir os impulsos emocionais próprios e controlá-los em seu benefício. A dimensão interpessoal está relacionada com a relação do indivíduo com os outros, destacando-se a componente de empatia ou de "sintonia emocional", traduzida pela capacidade de compreender a natureza e as motivações das emoções dos outros, avaliando as situações a partir da perspectiva alheia. Posteriormente, Mayer e Salovey (1997) propuseram uma revisão do conceito de IE que reduz o espectro da sua incidência, tornando-o mais objetivo e mensurável. Este modelo concentra a IE em quatro capacidades específicas: a percepção e expressão ajustada de emoções; a utilização de emoções como facilitadoras de raciocínio; a compreensão da emoção; e o controle de emoções em si próprio e nos outros. 
Apesar das diferenças entre as perspectivas dos diversos autores, parece convergente a idéia de que a IE integra uma dimensão interna (associada à compreensão das emoções e ao seu controle) e uma dimensão externa (relativa à compreensão e regulação das emoções dos outros). Estas são as duas dimensões da IE abordadas neste estudo, designadas genericamente como autocontrole (componente intrapessoal) e empatia (componente interpessoal).

Quanto ao papel que a IE pode desempenhar em processos negociais, já existe um conjunto alargado de autores que defendem o efeito decisivo que as emoções podem ter nos resultados alcançados em contextos de negociação (THOMPSON; NADLER; KIM, 1999). Conjugar a racionalidade (associada ao autocontrole) com a emotividade é reconhecidamente uma característica importante para os negociadores. Fisher e Davis afirmam que um bom negociador deve saber "expressar os seus sentimentos de forma apropriada [ao mesmo tempo que] permanece racional em face desses mesmos sentimentos” (FISHER; DAVIS, 1987, p. 118).

Numa investigação sobre o impacto das emoções na negociação, Thompson, Medvec, Seiden e Kopelman (2000) identificaram três estilos emocionais distintos:

1. O Negociador Racional. É aquele que não expressa as suas emoções, acreditando que se o fizer estará a dar um sinal de fraqueza e que exprimir emoções o torna mais vulnerável. A ausência ou repressão das emoções é consistente com os princípios da racionalidade. Nierenberg refere que "as pessoas num estado emocional (positivo ou negativo) não querem pensar, e estão particularmente susceptíveis ao poder de sugestão de um oponente astucioso" (NIERENBERG, 1968, p. 46). Também Fisher, Ury e Patton (1991) concordam com esta posição, defendendo que as emoções podem conduzir a um impasse ou ao fim da negociação.

2. O Negociador Positivo. Em vez de reprimir a emoção, o negociador positivo acredita que exprimir emoções positivas pode trazer vantagens. Estudos empíricos confirmaram que a expressão de emoções positivas permite obter melhores resultados (KUMAR, 1997; KRAMER; POMMERSENKE; NEWTON, 1993). Carnevale e Isen (1986) concluíram que a expressão de emoções positivas aumenta a criatividade, levando a soluções inovadoras, torna os indivíduos mais cooperativos, dispostos a partilhar mais informação, gerando mais alternativas. No entanto, a expressão de emoções pode ter conseqüências negativas. Os negociadores que exprimem sentimentos positivos prestam, por norma, menos atenção aos argumentos da outra parte, o que os torna vulneráveis à utilização de táticas fraudulentas por parte de negociadores competitivos. 
3. O Negociador Negativo. Outra abordagem possível é a expressão de sentimentos negativos, como a raiva, a impaciência, a indignação ou o ódio. Este tipo de negociador usa a emoção para tentar coagir a outra parte a ceder às suas exigências. Quando existe uma expressão verdadeira de sentimentos negativos, o comportamento do negociador irá afetar a relação que mantém com a outra parte, levando muitas vezes à retaliação, o que resulta na escalada do conflito (ALLRED, 1999; BIES; TRIPP, 1998) e, consequentemente, a negociações pouco produtivas. Allred et al. (1997), concluíram que, quando os negociadores expressam sentimentos negativos em relação à outra parte, obtêm piores resultados do que os que expressam emoções positivas. No entanto, a expressão de sentimentos negativos pode funcionar também como alerta de que existe um problema, motivando as partes a enfrentar esse problema e a procurar uma solução que o resolva (DAVIDSON; GREENHALGH, 1999).

A utilização da emoção pode ser genuína ou simplesmente uma tática para conseguir alcançar os objetivos pretendidos. Barry (1999) questionou um conjunto de negociadores sobre a eficácia e a pertinência da manipulação de emoções (como a antipatia, a raiva, a simpatia, o entusiasmo ou a impaciência) enquanto tática negocial. Os resultados do estudo sugerem que os negociadores consideram eticamente mais aceitável a utilização de emoções premeditadas como tática do que qualquer outro tipo de estratégia de dissimulação, como a transmissão de informação falsa ou o não cumprimento de promessas. Para além da pertinência da manipulação emocional, os negociadores revelaram também maior tolerância ética à utilização de emoções positivas do que no caso de emoções negativas.

No âmbito da dimensão interpessoal da IE, destaca-se, nos estudos sobre negociação, o conceito que muitos autores definem como a percepção da perspectiva contrária (que pode ser equiparada ao conceito de empatia, nos termos propostos por Salovey e por Goleman). A capacidade de compreender a perspectiva da outra parte, especialmente na preparação da negociação, permite ao negociador, por exemplo, estar apto a responder eficazmente aos seus argumentos. Sebenius (2001) argumenta que uma das principais causas para o insucesso na negociação é a negligência dos pontos de vista contrários. Segundo o autor, "perceber os interesses e pontos de vista do seu oponente, construindo uma solução em que a outra parte se reveja, é a chave para a criação conjunta de valor” (p. 88) e consequentemente para o êxito de uma negociação. Neale e Northcraft (1991) definem a percepção da perspectiva contrária como “a capacidade de um negociador compreender o ponto de vista da outra parte e consequentemente poder prever as suas estratégias e táticas negociais” (p. 174). Desta forma, esta capacidade de percepção influencia não só os resultados como também o processo negocial, nomeadamente através do aumento das concessões 
pelo seu oponente (NEALE; BAZERMAN, 1983). Kemp e Smith (1994) concluíram ainda que os indivíduos com maior capacidade de percepção da perspectiva contrária conseguem melhores resultados globais.

Atualmente, a investigação sobre IE apresenta já um conjunto significativo de estudos teóricos, caminhando rapidamente no sentido da formalização e do consenso acerca das componentes que constituem o conceito. Os trabalhos de natureza empírica estão ainda limitados pela inexistência de escalas apropriadas, uma vez que as existentes ainda se encontram em desenvolvimento ou em processo de validação (MAYER et al., 2001).

\section{Metodologia da Investigação}

Em vez de recorrer às metodologias de investigação habitualmente utilizadas no campo da negociação, que envolvem o estudo de uma ou de várias características num ambiente negocial simulado, optou-se por estudar as percepções de gerentes de empresas sobre a importância de algumas características pessoais do negociador para o êxito da negociação. Esta opção de investigação permite testar um maior número de variáveis de inteligência (não ficando limitada àquelas para as quais já existem escalas validadas). Trata-se portanto de um estudo com características exploratórias, dado que se pretende investigar um fenômeno sobre o qual ainda não existe informação suficiente para estabelecer uma teoria que o sustente (RICHARDSON, 1985), procurando, para o efeito, analisar variáveis que permitam formular hipóteses de investigação mais exatas para estudos futuros (SELLTIZ; WRIGHTSMAN; COOK, 1987). Por outro lado, a natureza desta pesquisa encerra igualmente uma dimensão descritiva na medida em que se propõe descrever o pensamento e as características de uma determinada população perante um dado fenômeno, recorrendo a técnicas padronizadas de coleta de dados como os questionários (GIL, 1999).

A população desta pesquisa é constituída pelos gerentes que integram a Diretoria das 500 maiores empresas não financeiras portuguesas ${ }^{(1)}$. Esta população aumenta a fiabilidade e coerência das respostas obtidas, uma vez que os quadros superiores destas organizações têm, quase sempre, um trajeto e uma experiência pessoal marcada por diversas situações negociais. Por outro lado, ao centrar o estudo nas 500 maiores empresas portuguesas é assegurada uma representatividade satisfatória do tecido empresarial nacional, dado que no conjunto destas empresas estão incluídas organizações de diversas dimensões e diversos sectores de atividade. Para formar a amostra inicial foram selecionados aleatoriamente dois gerentes de cada uma das 500 empresas, totalizando inicialmente 1000 dirigentes. 
Este número foi reduzido para 764 gerentes após a eliminação de redundâncias (gerentes que pertencem aos quadros de mais do que uma das empresas estudadas) e de dirigentes de nacionalidade não portuguesa (a fim de minimizar o eventual efeito de contextos culturais distintos).

O número ainda reduzido de estudos que abordem o tema da inteligência na negociação e a inexistência na literatura de instrumentos de pesquisa solidamente validados sobre este assunto obrigou à adaptação de questionários utilizados por outros autores em pesquisas semelhantes, porém com objetivos distintos. Assim, as variáveis escolhidas para estudar as características que definem um negociador eficaz e o formato do questionário utilizado neste estudo, resultaram de uma adaptação do inquérito originalmente desenvolvido por Karrass (1968), adaptado posteriormente por Hammond (1979). Estes autores conduziram pesquisas com diferentes objetivos, embora tivessem o mesmo pressuposto de base: os negociadores necessitam de possuir um determinado conjunto de características, pois estas têm uma influência determinante no processo negocial e, consequentemente, nos resultados da negociação. A partir dos questionários elaborados por estes autores, foram selecionadas apenas as questões relevantes para esta pesquisa.

Para avaliar a percepção dos gerentes portugueses sobre a importância de características da inteligência para a eficácia de um negociador, foi elaborado um questionário com duas partes. Na primeira parte foi questionada a opinião dos gerentes relativamente a importância de dez características de inteligência. $\mathrm{Na}$ segunda parte era pedido aos gerentes que avaliassem um conjunto de comportamentos relacionados com o papel desempenhado pela emoção na negociação. Para o efeito foi construída uma escala de seis itens baseada no trabalho desenvolvido por Barry (1999), onde este aborda a utilização de táticas de manipulação da emoção em contextos negociais. O objetivo desta parte é complementar a percepção sobre a pertinência das características individuais com a opinião dos gerentes sobre a validade e importância de determinados comportamentos diretamente associados à expressão e controle de emoções.

\section{Análise e Interpretação dos Resultados}

Dos 764 questionários enviados aos gerentes das 500 maiores empresas portuguesas em Maio de 2001, foram obtidas 255 respostas. Destas, 24 foram anuladas devido à detecção de irregularidades no preenchimento do questionário. As 231 respostas válidas recebidas permitem efetuar uma primeira análise de algumas características demográficas que caracterizam a amostra. O elevado número de respostas (231), associado a uma taxa de resposta de 30,2\%, atesta a 
relevância atribuída ao tema e garante a representatividade do estudo. Os gerentes da amostra apresentam, em média, uma idade aproximada de 50 anos e 25 anos de experiência profissional. Relativamente ao gênero dos inquiridos, a amostra apresenta uma predominância do gênero masculino - dos 224 inquiridos que indicaram o gênero, apenas 20 (menos de 9\%) eram do gênero feminino.

\section{As Características do Negociador}

A primeira parte do questionário destinava-se a avaliar a percepção dos gerentes sobre a importância da inteligência nas atividades de negociação, requerendo para o efeito a sua avaliação de 10 características da inteligência, associadas a aspectos cognitivos e emocionais. A Tabela 1 resume a opinião dos gerentes portugueses relativamente a essas características, avaliadas numa escala de 5 pontos ( 1 - nada importante a 5 - muito importante):

\section{Tabela 1: Importância das Características dos Negociadores}

\begin{tabular}{|c|c|c|c|c|c|c|c|c|}
\hline \multirow{2}{*}{ Característica } & \multirow{2}{*}{ N. ${ }^{\circ}$ casos } & \multicolumn{5}{|c|}{ Freqüências Relativas } & \multirow{2}{*}{ Média } & \multirow{2}{*}{$\begin{array}{l}\text { Desvio- } \\
\text { Padrão }\end{array}$} \\
\hline & & (1) & (2) & (3) & (4) & (5) & & \\
\hline $\begin{array}{l}\text { 1. Capacidade para pensar com } \\
\text { clarividência e rapidamente sob } \\
\text { pressão e incerteza }\end{array}$ & 231 & - & $1 \%$ & $5 \%$ & $32 \%$ & $62 \%$ & 4,55 & 0,62 \\
\hline $\begin{array}{l}\text { 2. Criatividade para ultrapassar } \\
\text { obstáculos e dificuldades }\end{array}$ & 231 & - & $1 \%$ & $4 \%$ & $41 \%$ & $54 \%$ & 4,49 & 0,60 \\
\hline 3. Capacidade de julgamento & 231 & - & - & $8 \%$ & $43 \%$ & $49 \%$ & 4,41 & 0,64 \\
\hline $\begin{array}{l}\text { 4. Capacidade de análise e de } \\
\text { resolução de problemas }\end{array}$ & 231 & - & $2 \%$ & $7 \%$ & $48 \%$ & $43 \%$ & 4,32 & 0,65 \\
\hline $\begin{array}{l}\text { 5. Capacidade para perceber os } \\
\text { sentimentos e pontos de vista do } \\
\text { seu oponente }\end{array}$ & 231 & - & - & $9 \%$ & $43 \%$ & $48 \%$ & 4,39 & 0,68 \\
\hline $\begin{array}{l}\text { 6. Percepção das necessidades não } \\
\text { explícitas e das reações da sua } \\
\text { organização e da do seu oponente }\end{array}$ & 231 & - & - & $14 \%$ & $48 \%$ & $38 \%$ & 4,25 & 0,72 \\
\hline $\begin{array}{l}\text { 7. Capacidade para perceber o seu } \\
\text { poder negocial e utilizá-lo para } \\
\text { atingir os seus objetivos }\end{array}$ & 231 & - & $2 \%$ & $12 \%$ & $48 \%$ & $38 \%$ & 4,23 & 0,70 \\
\hline $\begin{array}{l}\text { 8. Capacidade para manter uma } \\
\text { atitude racional }\end{array}$ & 231 & - & $1 \%$ & $12 \%$ & $57 \%$ & $30 \%$ & 4,16 & 0,66 \\
\hline 9. Autocontrole & 231 & $1 \%$ & $3 \%$ & $15 \%$ & $50 \%$ & $32 \%$ & 4,10 & 0,78 \\
\hline $\begin{array}{l}\text { 10. Capacidade para responder } \\
\text { emotivamente }\end{array}$ & 231 & $10 \%$ & $20 \%$ & $44 \%$ & $21 \%$ & $5 \%$ & 2,89 & 1,00 \\
\hline
\end{tabular}


Pela análise destes resultados, pode concluir-se que quase todas as características estudadas têm, na opinião dos gerentes inquiridos, uma grande importância para o sucesso da atividade negocial. De todas as características mencionadas, a capacidade para pensar com clarividência e rapidamente sob pressão e incerteza foi considerada a mais importante (Média 4,55), confirmando que, tendo em conta a ambigüidade e a pressão que normalmente rodeiam as negociações empresariais, a capacidade de assimilar e interpretar a informação disponível com clareza e lucidez é fundamental para o êxito dos negociadores. Destacam-se ainda outras características como a criatividade $(4,49)$, a capacidade de avaliação da realidade envolvente $(4,41)$ e a capacidade de resolução de problemas $(4,32)$. Por outro lado, as características relacionadas com a percepção da perspectiva contrária são consideradas, unanimemente, como competências fundamentais para negociar com eficácia. Quanto ao controle e utilização da emoção na negociação, parece consensual que um negociador deve conseguir controlar as suas emoções e o impulso que delas decorre; já relativamente à capacidade de utilizar a emoção como tática negocial, os inquiridos não lhe reconhecem importância elevada. Uma média de apenas 2,98 significa que os gerentes não acreditam que a utilização da emoção, seja positiva ou negativa, lhes traga grandes vantagens negociais. Este resultado parece contrariar a crescente importância das dimensões da inteligência emocional, reconhecidas por diversos autores como características fundamentais para o sucesso dos indivíduos em contextos empresariais. Pode, neste caso particular, presumir-se a eventualidade de ter sido feita uma interpretação distorcida da pergunta, associando o responder emotivamente ao responder agressivamente. A ocorrência desta confusão interpretativa em número significativo de casos limitaria a interpretação destas respostas, porém não há razões para assumir que foi isso que aconteceu.

Tendo em conta a complexidade e dinamismo dos ambientes empresariais, os negociadores necessitam de desenvolver eficazmente a sua capacidade de percepção do ambiente negocial para poderem negociar com sucesso. Por isso mesmo, não é de estranhar a importância atribuída a todas as características relacionadas com a forma como os negociadores interpretam e, consequentemente, reagem às condições ambientais percepcionadas. De acordo com os resultados obtidos, pode concluir-se que a capacidade cognitiva é considerada fundamental na explicação do processo negocial. O autocontrole das emoções também assume, na perspectiva dos gerentes portugueses, um papel importante para garantir o êxito de uma negociação. De alguma forma, esta idéia confirma a pouca importância atribuída à utilização de emoções como táticas negociais para provocar reações na outra parte que melhorem os resultados da negociação. Este resultado contraria alguma literatura sobre a emoção na negociação, uma vez que diversos investigadores têm defendido que a expressão de emoções, especialmente positivas, é pertinente e produz resultados positivos. 


\section{As Dimensões da Inteligência do Negociador}

Com o objetivo de avaliar a interdependência entre variáveis e a estrutura conceptual da sua relação, efetuou-se a análise fatorial de componentes principais (AFCP). Este procedimento permite perceber até que ponto diferentes variáveis têm subjacente o mesmo conceito, identificando as que estão relacionadas entre si e as que não estão. O teste de esfericidade de Bartlett (sig. 0,000) indica que existe uma correlação entre as variáveis suficientemente grandes para justificar a fatorização da matriz dos coeficientes de correlação. Confirmando este resultado, a medida de adequação da amostra (MSA - measure of sampling adequacy) dada pelo índice KMO é 0,790 , o que reforça a pertinência de efetuar esta análise, uma vez que o limite mínimo habitualmente considerado satisfatório para prosseguir um estudo desta natureza é de 0,7 (HAIR et al., 1998; SHARMA, 1996). A análise da matriz antiimagem permite concluir que existe adequação de todas as variáveis à AFCP, uma vez que os valores da diagonal principal são superiores a 0,7 (sendo a única exceção a variável capacidade para responder emotivamente, que registra um MSA de 0,47 ) e os valores fora da diagonal são residuais. Foram extraídos três fatores com autovalor superior a 1, que explicam, no seu conjunto, $63 \%$ da variância total. Na Tabela 2 são apresentadas as variáveis associadas a cada fator, após a rotação Varimax:

\section{Tabela 2: As Dimensões da Inteligência dos Negociadores}

\section{CARgas FAtoriais}

\begin{tabular}{lc}
\hline Capacidade de análise e de resolução de problemas & 0,823 \\
Capacidade de julgamento & 0,690 \\
Criatividade para ultrapassar obstáculos e dificuldades & 0,668 \\
$\begin{array}{l}\text { Capacidade para perceber o seu poder negocial e de utilizá-lo para atingir os } \\
\text { seus objetivos }\end{array}$ & 0,611 \\
$\begin{array}{l}\text { Capacidade para pensar com clarividência e rapidamente sob pressão e } \\
\text { incerteza }\end{array}$ & 0,598 \\
$\begin{array}{l}\text { Capacidade para perceber os sentimentos e pontos de vista do seu oponente } \\
\text { Percepção das necessidades não explícitas e das reações da sua organização e } \\
\text { da do seu oponente }\end{array}$ & $\mathbf{0 , 8 8 2}$ \\
$\begin{array}{l}\text { Capacidade para responder emotivamente (emotividade) } \\
\text { Capacidade para manter uma atitude racional (racionalidade) }\end{array}$ & 0,698 \\
$\begin{array}{l}\text { Autocontrole, especialmente das suas emoções e a sua visibilidade } \\
\text { Alpha de Cronbach }\end{array}$ & 0,642 \\
\hline $\begin{array}{l}\text { Nota: só aparecem as cargas com valor absoluto superior a 0,400 (RUMMEL, 1970; STEVENS, } \\
\text { 1992). }\end{array}$ & $\mathbf{0 , 0 , 8 6 4}$ \\
\hline
\end{tabular}


Os três fatores identificados podem ser interpretados à luz das duas dimensões de inteligência abordadas neste estudo: a Inteligência Cognitiva e a Inteligência Emocional. O primeiro fator está relacionado com o modo como os negociadores interpretam a informação disponível e a ela reagem, para gerarem alternativas e soluções que lhes permitam alcançar os seus objetivos negociais. Este fator inclui as variáveis consideradas mais importantes pelos gerentes e que sintetizam, no seu conjunto, as idéias subjacentes ao conceito de Inteligência Cognitiva, nos termos definidos por Gottfredson (1997) - uma capacidade mental que envolve o raciocínio, a predisposição para a resolução de problemas e a compreensão de idéias complexas - e por Ree e Earles (1991) - capacidade individual de apreender e processar informação.

O segundo fator está relacionado com a forma como o negociador percepciona as motivações e os interesses do seu oponente. Este fator reúne as variáveis que avaliam a percepção da perspectiva contrária, podendo ser genericamente designado por Inteligência Interpessoal. Este tipo de percepção, associada ao conceito de empatia desenvolvido no âmbito da IE, respeita à capacidade de compreender as necessidades e pontos de vista da outra parte (NEALE; NORTHCRAFT, 1991).

O último fator inclui a racionalidade e o autocontrole e, com peso negativo, a capacidade para responder emotivamente. As duas primeiras variáveis sugerem que este fator está relacionado com uma dimensão da inteligência emocional associada ao controle e gestão das emoções. Esta dimensão pode ser resumida no conceito de Inteligência Intrapessoal, definida como a capacidade de compreender os impulsos emocionais e de controlá-los em benefício próprio (GOLEMAN, 1995). A presença, neste fator, com peso negativo, da capacidade para responder emotivamente, reforça a possibilidade já levantada de os inquiridos terem interpretado a resposta emotiva como resposta emocionalmente descontrolada. Esta hipótese é consistente com a interpretação dada a este fator. O valor reduzido do Alpha de Cronbach para este fator pode igualmente ser justificado por esta razão.

A identificação desses três fatores atesta a adequação das variáveis utilizadas à teoria existente sobre inteligência cognitiva e emocional, uma vez que agrupa essas variáveis em conjuntos destinados desde o início a medir as dimensões específicas da inteligência que foram identificadas. É igualmente interessante destacar o fato de os gerentes portugueses darem maior importância à Inteligência Cognitiva do que aos aspectos emocionais. Esta postura parece contrariar as posições defendidas por diversos autores que atribuem maior valor à inteligência emocional do que à complexidade cognitiva na comunicação e nas relações interpessoais (KEMPER, 1999). Talvez a percepção dos gerentes 
portugueses esteja condicionada por fatores de ordem histórica, social e cultural que caracterizam a generalidade das economias latinas e, especialmente, as européias.

A partir dos fatores identificados, aplicaram-se ainda alguns procedimentos estatísticos com vista a analisar a relação destes fatores com as características demográficas dos inquiridos. Assim, apesar de a amostra apenas incluir 9\% de mulheres (20 respostas), limitando a comparação entre gêneros, a análise da variância revelou que apenas foram encontradas diferenças estatisticamente significativas na maior importância que as mulheres atribuem à dimensão interpessoal da Inteligência (sig. 0,036). Este resultado pode ser explicado pela tendência para uma maior sensibilidade e preocupação na gestão das relações interpessoais que o padrão do comportamento feminino habitualmente revela. Quanto à idade, considerando dois grupos de gerentes divididos a partir da média de idades da amostra (50 anos), os resultados mostraram que os gerentes mais idosos atribuem maior importância à Inteligência Cognitiva (sig. 0,036). Talvez os executivos mais velhos desenvolvam um pragmatismo natural perante os negócios que promova a valorização da racionalidade em detrimento dos aspectos emocionais - e supostamente mais precipitados - característicos dos mais jovens.

Por fim, tanto a experiência profissional e o sector de atividade parecem não ter impacto nas percepções dos gerentes. Este resultado é interessante, pois pode indicar que no nível da alta direção de empresas o tipo de negociações que ocorrem não diferem com o sector de atividade, uma vez que estão mais relacionados com a estratégia corporativa e menos com a estratégia específica à sua área de negócio.

\section{O Papel da Emoção na Negociação}

A segunda parte do questionário visava avaliar a concordância dos gerentes em relação a um conjunto de comportamentos relacionados com o papel desempenhado pela emoção na negociação. Os comportamentos avaliados dizem respeito ao autocontrole e repressão da emoção, e à expressão simulada ou genuína de emoções positivas e negativas. A opinião dos inquiridos foi medida numa escala de Lickert de 7 pontos (1 - absolutamente em desacordo; 7 absolutamente de acordo), sendo os resultados apresentados em seguida na Tabela 3: 


\section{Tabela 3: A Emoção na Negociação}

\begin{tabular}{|c|c|c|c|c|c|c|c|c|}
\hline & (1) & (2) & (3) & (4) & (5) & (6) & (7) & MÉDIA \\
\hline $\begin{array}{l}\text { 1. Se um negociador se mantiver calmo em todas } \\
\text { as circunstâncias terá uma enorme vantagem. }\end{array}$ & - & - & $3 \%$ & $2 \%$ & $11 \%$ & $47 \%$ & $37 \%$ & 6,13 \\
\hline $\begin{array}{l}\text { 2. Um negociador deve manter uma expressão } \\
\text { impassível: nunca deve transparecer as suas } \\
\text { emoções até à conclusão do acordo. }\end{array}$ & $3 \%$ & $12 \%$ & $13 \%$ & $12 \%$ & $26 \%$ & $29 \%$ & $6 \%$ & 4,55 \\
\hline $\begin{array}{l}\text { 3. Um negociador deve expressar emoções } \\
\text { positivas (satisfação, simpatia, afeto, entusiasmo) } \\
\text { de uma forma natural e genuína. }\end{array}$ & $2 \%$ & $6 \%$ & $17 \%$ & $21 \%$ & $29 \%$ & $17 \%$ & $9 \%$ & 4,52 \\
\hline $\begin{array}{l}\text { 4. Um negociador deve simular emoções positivas } \\
\text { (satisfação, simpatia, afeto, entusiasmo) se sentir } \\
\text { que isso melhora a sua posição negocial. }\end{array}$ & $27 \%$ & $28 \%$ & $15 \%$ & $10 \%$ & $12 \%$ & $6 \%$ & $3 \%$ & 2,91 \\
\hline $\begin{array}{l}\text { 5. Um negociador deve expressar emoções } \\
\text { negativas (desconforto, raiva, indignação, } \\
\text { impaciência) se se sentir descontente ou enganado. }\end{array}$ & $11 \%$ & $29 \%$ & $26 \%$ & $12 \%$ & $13 \%$ & $6 \%$ & $3 \%$ & 3,16 \\
\hline $\begin{array}{l}\text { 6. Um negociador deve simular emoções negativas } \\
\text { (desconforto, raiva, indignação, impaciência) se } \\
\text { sentir que isso melhora a sua posição negocial. }\end{array}$ & $38 \%$ & $26 \%$ & $15 \%$ & $10 \%$ & $7 \%$ & $4 \%$ & - & 2,33 \\
\hline
\end{tabular}

A partir da tabela anterior, pode concluir-se que em relação à questão $\mathbf{1}$ as opiniões são quase consensuais. Mais de $95 \%$ dos gerentes consideram que é fundamental manter uma atitude tranqüila e calma durante a negociação. Destes, $37,2 \%$ estão absolutamente de acordo e $47,2 \%$ bastante de acordo que uma atitude calma, sem ansiedade e nervosismo, proporciona enorme vantagem ao negociador, uma vez que poderá avaliar racionalmente as alternativas disponíveis para escolher aquela que melhor defenda os seus interesses. Já em relação à expressão de emoções, as opiniões dividem-se. A maioria dos inquiridos considera que é importante não exprimir qualquer emoção até a conclusão do acordo (questão 2). Contrariamente, 27,3\% dos inquiridos acredita que um negociador pode, ou deve, exprimir emoções, pois isso não só não o prejudica como pode beneficiá-lo. Este resultado acaba por confirmar a pouca importância atribuída à capacidade para responder emotivamente, uma vez que a expressão de emoções pode pôr em perigo a eficácia do processo de tomada de decisão em negociação. Já quando questionados se um negociador deve exprimir, naturalmente, as suas emoções, os inquiridos tornam a dividir-se. Se as emoções positivas, como o afeto, a simpatia e o entusiasmo (questão 3), parecem ser aceitas pela maioria dos gerentes, uma vez que levam ao estabelecimento de uma relação próxima com o oponente, as emoções negativas, como a indignação ou a impaciência (questão 5), por seu lado, são rejeitadas, pois podem levar a uma escalada do conflito com conseqüências negativas para os resultados da negociação e para a relação entre as partes. Esses resultados confirmam as conclusões de diversos estudos anteriores, uma vez que os comportamentos 
positivos são mais valorizados do que os negativos. Curiosamente, apesar de concordarem que um negociador não deve deixar transparecer qualquer emoção até a conclusão do acordo, os gerentes concordam igualmente com a expressão de sentimentos positivos. Isto poderá significar que comportamentos como a simpatia e a boa disposição são aceitos como forma de estabelecer uma relação cordial com a outra parte, não denunciando necessariamente a posição negocial. A expressão de emoções negativas é claramente rejeitada - 66\% dos inquiridos discordam da sua utilização - na medida em que tornam os processos negociais pouco produtivos. No entanto, a expressão de sentimentos negativos pode ser um alerta de que existe um problema, o que pode motivar as partes a confrontar esse problema e a procurar uma solução que o resolva. Por outro lado, a manipulação da emoção como tática negocial parece ser condenada pelos inquiridos. Estes consideram que tanto a simulação de emoções positivas (questão 4) como de emoções negativas (questão 6) são comportamentos eticamente reprováveis e que devem ser evitados, sendo estes resultados consistentes com as conclusões de outros autores (BARRY, 1999). Da análise dos resultados, conclui-se ainda que os inquiridos consideram preferível expressar emoções negativas genuínas, como forma de demonstrar desagrado com a situação (questão 5), a simular emoções positivas (questão 4). Apenas 20\% dos gerentes (dos quais 3\% em absoluta concordância) concordam com a utilização tática de emoções positivas, enquanto relativamente à expressão de emoções negativas, só $11 \%$ demonstraram a sua concordância.

Conclui-se, a partir desta análise, que existe uma preferência por posturas negociais de autocontrole emocional em detrimento da expressão livre de emoções. Esse resultado corrobora a idéia de que a negociação é tradicionalmente vista como processo racional onde a interferência da emoção é considerada uma distração (DAVIDSON; GREENHALGH, 1999). Apesar desta sobrevalorização da racionalidade, os gerentes aprovam a utilização de emoções positivas e reprovam a possibilidade de manipulação de qualquer tipo de emoção.

\section{Conclusão}

Com vista a estudar o papel da inteligência nos processos negociais, esta investigação partiu da distinção entre Inteligência Cognitiva e Inteligência Emocional. Com base num estudo empírico realizado por meio de questionário enviado aos gerentes das 500 maiores empresas portuguesas, pretendeu-se avaliar a percepção destes profissionais sobre a importância de algumas características cognitivas e emocionais para o bom desempenho dos negociadores. 
Os resultados sugerem uma valorização maior dos aspectos cognitivos em detrimento das características emocionais do negociador. É atribuída maior importância à capacidade de compreensão, articulação e utilização da informação disponível do que aos mecanismos de percepção, controle e gestão de emoções. A inteligência, a criatividade, a capacidade de análise e, com alguma evidência, a capacidade para pensar rápida e com clareza sob pressão e incerteza são características que os inquiridos consideram muito importantes para negociar com sucesso. Estes resultados confirmam alguma literatura que defende a negociação como ato essencialmente racional que dispensa a intervenção frequentemente perturbadora da emotividade. No entanto, deve ser mencionado que os aspectos relacionados com a emoção, apesar de terem um apoio menos entusiasmado, foram, mesmo assim, destacados como importantes para o êxito de uma negociação. Um resultado imprevisto diz respeito à pouca importância atribuída à capacidade para responder emotivamente. Quando a investigação atual sugere que a inteligência emocional pode desempenhar papel mais importante do que a complexidade cognitiva nas relações interpessoais, este resultado vem, de alguma forma, contrariar a importância da gestão das emoções nas relações com os outros. Poderá neste caso, como já foi referido, ter ocorrido uma interpretação distorcida da pergunta que levou à rejeição, por parte dos executivos, de manifestações emotivas em processos negociais.

A aplicação da análise fatorial de componentes principais aos resultados alcançados permitiu identificar três fatores que combinam de forma consistente as características de inteligência estudadas. Assim, destacou-se um fator de Inteligência Cognitiva, um fator de Inteligência Interpessoal e outro fator de Inteligência Intrapessoal. Estes fatores permitem validar as variáveis utilizadas para medir as dimensões da inteligência e confirmam novamente a preferência dos executivos pela racionalidade e pela cognição em contexto negocial.

Finalmente, ao serem questionados sobre a pertinência e validade de alguns comportamentos negociais, os inquiridos reforçaram a importância da manutenção de uma postura emocionalmente neutra e controlada. Ainda assim, revelaram maior aceitação da expressão de emoções positivas (afeto, simpatia, alegria, entusiasmo) do que de emoções negativas (indignação, raiva, descontentamento, desprezo). A análise dos resultados revelou também reprovação clara da manipulação tática de emoções, sejam positivas ou negativas. Pode concluir-se que, segundo os executivos das maiores empresas portuguesas, o controle é útil, mas o impacto da sua simulação não é aconselhável, demonstrando algumas preocupações de natureza ética que deverão ser exploradas em estudos posteriores.

\section{Artigo recebido em 21.10.2003. Aprovado em 24.06.2004.}




\section{Notas}

${ }^{1}$ As 500 maiores empresas portuguesas têm um faturamento anual que varia entre 36 e 5.650 milhões de euros.

${ }^{2}$ Para avaliar a consistência interna da associação entre as variáveis que compõem cada fator, utilizou-se o Alpha de Cronbach, que revelou valores satisfatórios, considerando o caráter exploratório do estudo e a utilização experimental do instrumento de medida.

\section{RefERÊnCIAs Bibliográficas}

ALLRED, K. et al.

The influence of anger and compassion in negotiation performance. Organizational Behavior and Human Decision Processes, New York, v. 70, n. 3, p. 175-187, June 1997.

\section{ALLRED, K.}

Anger-driven retaliation: toward and understanding of impassioned conflict in organizations. In: BIES R.; LEWICKI, R.; SHEPPARD, B. (Eds.) Research on Negotiation in Organizations. Greenwich: JAI Press, v. 7, p. 27-58, 1999.

\section{BARON, R.}

Personality and organizational conflict: Effects of type a behavior and self-monitoring. Organizational Behavior and Human Decision Processes, New York, v. 44, n. 2, p. 281-296, Oct. 1989.

BARRY,B.;

FRIEDMAN, R.

Bargainer characteristics in distributive and integrative negotiation. Journal of Personality and Social Psychology, Washington, v. 74, n. 2, p. 345-359, Feb. 1998.
BARRY,B.

The tactical use of emotion in negotiation. In: BIES, R.; LEWICKI, R.; SHEPPARD, B. (Eds.) Research on Negotiation in Organizations. Greenwich: JAI Press, v. 7, p. 93-121, 1999.

BAZERMAN, M.;

NEALE, $M$.

Negotiating Rationally. New York:

Free Press, 1992.

\section{BAZERMAN, M.;}

CURHAN, J.;

VALLEY, K.

Negotiation. Annual Review of

Psychology, Palo Alto, v. 51, p. 279-

314, 2000.

\section{BIES, R.;}

TRIPP, T.

Revenge in organizations: The good, the bad and the ugly. In: GRIFFIN, R.; O’LEARY-KELLY,A.; COLLINS, J. (Eds.) Dysfunctional Behavior in Organizations, Volume 1: violent behavior in organizations, Greenwich: JAI Press, v. 1, p. 49-68, 1998. 
CARNEVALE, P.;

\section{ISEN, A.}

The influence of positive affect and visual access on the discovery of integrative solutions in bilateral negotiations. Organizational Behavior and Human Decision Processes, New York, v. 37, n. 1, p. 1-13, Feb. 1986.

DAVIDSON, M.;

GREENHALGH,L.

The role of emotion in negotiation: The impact of anger and rage. In: BIES R.; LEWICKI R.; SHEPPARD, B. (Eds.) Research on Negotiation in Organizations. Greenwich: JAI Press, v. 7, p. 3-26, 1999.

DE DREU, C.;

KOOLE, S.;

OLDERSMA, F.

On the seizing and freezing of negotiator inferences: Need for cognitive closure moderates the use of heuristics in negotiation. Personality and Social Psychology Bulleti, Thousand Oaks, v. 25, n. 3, p. 348-362, Mar. 1999.

FISHER, R.;

DAVIS, W.

Six basic interpersonal skills for a negotiator's repertoire. Negotiation Journal, New York, v. 3, p. 117-122, Apr. 1987.

FISHER, R.;

URY, W.;

PATTON, B.

Como Conduzir uma Negociação?

Porto: Edições Asa, 1991.

FULMER, I.;

BARRY, B.

The "Smart Negotiator": Cognitive ability and emotional intelligence in negotiation. In: INTERNATIONAL ASSOCIATION FOR CONFLICT MANAGEMENT ANNUAL CONFERENCE, 15, 2002, Salt Lake City. Proceedings..., 2002. Disponível em: <http://www.ssrn.com>. Acesso em: 12 Dec. 2002.

GARDNER, $\mathrm{H}$.

Frames of mind: the theory of multiple intelligences. New York: Basic Books, 1983.

GIL,A.

Métodos e Técnicas de Pesquisa Social. 5. ed. São Paulo: Editora Atlas, 1999.

\section{GOLEMAN, D.}

Emotional Intelligence. New York: Bantam Books, 1995.

\section{GOTTFREDSON, L.}

Mainstream science on intelligence: an editorial with 52 signatories, history and bibliography. Intelligence, Norwood, v. 24, n. 1, p. 13-23, special issue 1997.

HAMMOND, J.

Characteristics of an effective negotiator. Harvard Business School Note, Boston, n. 179-029, 1979.

HAIR, J.;

ANDERSON, R., T. R.;

BLACK, W.

Multivariate Data Analysis. 5 th ed. New Jersey: Prentice-Hall, 1998.

HEGTVEDT, K.;

KILLIAN, C.

Fairness and emotions: reactions to the process and outcomes of negotiations. Social Forces, Chapel Hill, v. 78, n.1, p. 269-302, Sept. 1999. 
JESUÍNO, J.

A Negociação: estratégias e táticas. 3. ed. Lisboa: Texto Editora, 1992.

KARRASS, C.

A study of the relationship of negotiator skill and power as determinants of negotiation outcome. 1968. $283 \mathrm{f}$. Tese (Doctor of Business Administration - DBA) - University of Southern California, California.

KEMP, K.;

SMITH, W.

Information exchange, toughness, and integrative bargaining: The roles of explicit cues and perspectivetaking. International Journal of Conflict Management, Bowling Green, v. 5, p. 5-21, 1994.

KEMPER, C.

EQ vs. IQ. Communication World, San Francisco, v. 16, n. 9, p. 15-20, Oct./Nov. 1999.

KRAMER, R.;

POMMERSENKE, P.;

NEWTON, E.

The social context of negotiation: Effects of social identity and accountability on negotiator judgment and decision making. Journal of Conflict Resolution, Beverly Hills, v. 37, n. 4, p. 633-654, Dec. 1993.

KRAY,L.;

GALINSKY,A.;

THOMPSON, L.

Battle of sexes: Gender stereotypic confirmation and reactance in negotiations. Journal of Personality and Social Psychology, Washington, v. 80, n. 6, p. 942-958, June 2001.
KUMAR, R.

The role of affect in negotiations: an integrative overview. Journal of Applied Behavioral Science, Arlington, v. 33, n. 1, p. 84-100, Sept. 1997.

\section{KURTZBERG, T.}

Creative thinking, cognitive aptitude, and integrative joint gain: a study of negotiator creativity. Creativity Research Journal, Mahwah, v. 11, p. 283-293, 1998.

\section{LEPINE, J.;}

COLQUITT, J.;

EREZ,A.

Adaptability to changing task contexts: effects of general cognitive ability, conscientiousness and openness to experience. Personnel Psychology, Durham, v. 53, n. 3, p. 563-593, autumn 2000.

MAYER, J.;

SALOVEY,P.

What is emotional intelligence? In: SALOVEY, P.; SLUYTER, D.J. (Eds.) Emotional Development and Emotional Intelligence: educational implications, New York: Basic Books, 1997. p. 3-31.

MAYER, J. et al.

Emotional intelligence as a standard intelligence. Emotion, [S.L.], v. 1, p. 232-242, 2001.

\section{MINTZBERG, $\mathrm{H}$.}

The Nature of Managerial Work.

New York: Harper \& Row, 1973.

NEALE, M.;

BAZERMAN, M.

Cognition and rationality in negotiation. New York: Free Press, 1991. 
The role of perspective-taking ability in negotiation under different forms of arbitration. Industrial and Labor Relations Review, Ithaca, v. 36, n. 3, p. 378-388, Apr. 1983.

NEALE, M.;

NORTHCRAFT, G.

Behavioral negotiation theory: A framework for conceptualizing dyadic bargaining. In: CUMMINGS, l.; STAW, B. (Eds.), Research in Organizational Behavior, Greenwich: JAI Press, v. 13, p 147-190, 1991.

NEISSER, U. et al.

Intelligence: Knowns and unknowns. American Psychologist, Washington, v. 51, n. 2, p. 77-101, Feb. 1996.

\section{NIERENBERG, G}

The art of negotiation: Psychological strategies for gaining advantageous bargains. New York: Hawthorn Books, 1968.

\section{OGILVIE, J.;}

CARSKY, $M$.

Building emotional intelligence in negotiations. International Journal of Conflict Management, Bowling Green, v. 13, n. 4, p. 315-430, 2002.

\section{OLEKALNS, M.;}

SMITH, P.

Social value orientations and strategy choices in competitive negotiations.

Personality and Social Psychology Bulletin, Thousand Oaks, v. 25, n. 6, p. 657-668, June 1999.

PRUITT, D. G.;

LEWIS, S.A.

Development of integrative solutions in bilateral negotiation. Journal of Personality and Social Psychology, Washington, v. 31, p. 621-633, 1975.

PUTNAM, L.

Challenging the assumptions of traditional approaches to negotiation. Negotiation Journal, New York, v. 10, n. 4, p. 337-346, 1994.

REE, M.;

EARLES, J.

Predicting training success: not much more than g. Personnel Psychology, Durham, v. 44, n. 2, p. 321-332, summer 1991.

\section{RICHARDSON, R.}

Pesquisa Social: métodos e técnicas. São Paulo: Editora Atlas, 1985.

RUMMEL, R.

Applied Factor Analysis. Evanston: Northwestern University Press, 1970.

\section{SALOVEY,P.;}

MAYER, J.

Emotional Intelligence. Imagination Cognition and Personality, Farmingdale, v. 9, p. 185-211, 1990.

\section{SCHMIDT, F. et al.}

Joint relation of experience and cognitive ability with job performance: test of three hypotheses. Journal of Applied Psychology, Washington, v. 73, n. 1 p. 46-57, Feb. 1988.

\section{SEBENIUS, J.}

Six habits of merely effective negotiators. Harvard Business Review, Boston, v. 79, n. 4, p. 87-95, Apr. 2001. 
SELLTIZ, C.;

WRIGHTSMAN, C.;

COOK, L.

Métodos de Pesquisa nas Relações Sociais, 2. ed., v. 1, São Paulo: EPU, 1987.

\section{SHARMA, S.}

Applied Multivariate Techniques.

New York: John Wiley \& Sons, Inc, 1996.

STERNBERG, R.

The triarchic mind: A new theory of human intelligence. New York: Cambridge University Press, 1988.

\section{STEVENS, J.}

Applied multivariate statistics for social sciences, 2nd ed. Hillsdale: Lawrence Erlbaum Associates, 1992.

\section{THOMPSON, L.}

The Mind and Heart of the Negotiator. 2nd ed. New Jersey: Prentice Hall, 2001.
THOMPSON, L. et al.

Poker face, smiley face and rant ' $n$ ' rave: Myths and realities about emotion in negotiation. In: HOGG, M.; TINDALE, S. (Eds.) Blackwell handbook in social psychology, v. 3: Group processes. Cambridge: Blackwell Publishers, 2000. p. 139-163.

THOMPSON, L.;

NADLER, J.;

KIM, P.

Some like it hot: The case for emotional negotiator. In: THOMPSON, L.; LEVINE, J.; MESSICK, D. (Eds.) Shared cognition in organizations: the management of knowledge, Mahwah: Erlbaum, 1999. p. 139-161.

VAN KLEEF, G.;

DE DREU, C.;

MANSTEAD, A.

The interpersonal effects of anger and happiness in negotiations. Journal of Personality and Social Psychology, Washington, v. 86, n. 1, p. 57-76, Jan. 2004. 